\title{
Morphology investigation on direct current pulsed gas tungsten arc welded additive layer manufactured Ti6Al4V alloy
}

\author{
F. Wang, S. Williams, M. Rush \\ The Welding Engineering Research Centre, Cranfield University, MK43 OAl, UK \\ fude.wang@cranfield.ac.uk
}

\begin{abstract}
The effects of pulsed gas tungsten arc welding parameters on the morphology of additive layer manufactured Ti6AI4V has been investigated in this study. The peak current/base current ratio and pulse frequency are found to have no significant effect on the refinement of prior beta grain size. However, it is found that the wire feed rate has a considerable effect on the prior beta grain refinement at a given heat input. This is due to the extra wire input being able to supply many more heterogeneous nucleation sites and also results in a negative temperature gradient in the front of the liquidus which blocks the columnar growth and changes the columnar growth to equiaixal growth.
\end{abstract}

Keyword

Metal Additive Layer Manufacturing, Pulse Gas Tungsten Arc Welding, Ti6Al4V, Microstructure Refinement

\section{Introduction}

Metal additive layer manufacturing (ALM) is a technique that manufactures parts or components by adding material in the form of powder or wire without the need of tooling. During fabrication, a heat source (welding arc, electronic beam or laser) is moved along a path defined by the CAD file of the component to be produced, melting individual particles of powder or wire to form the component. Welding arc plus wire based ALM techniques have much higher deposition rate and lower cost comparing with laser, electronic beam and powder based additive layer manufacturing techniques.

Titanium alloys are used in aircraft structures and engines due to their high strength to weight ratio, excellent high temperature strength and corrosion resistance.

The conventional method of manufacturing titanium alloy components is a subtractive process in which the titanium component is machined out of a solid block of alloy. Up to $90 \%$ of the titanium alloy is machined away in this process and considering the high cost of titanium and the large amount of energy required for its processing, this greatly raises 
the production cost [1]. The use of additive layer manufacture technique can considerably reduce the buy-to-fly ratio of the alloy, reduces wastage and processing time, saves energy used for the manufacturing and gives more flexibility for the manufacturing of complex parts that would be difficult to achieve using the conventional process.

The latest generation of jetliners such as the Boeing 787 and Airbus A350 contain more than $50 \%$ by weight of composite materials. Aluminium alloys are electrochemically incompatible with carbon fibre polymer composites, forming a galvanic couple when placed in direct contact. This reason, coupled with the superior mechanical properties of titanium alloys, has lead to their increased usage in these airliners, with the Boeing 787 containing $15 \%$ by weight of titanium alloy [2].

Although metal additive layer manufacturing is an economic alternative method compared to conventional manufacturing methods like casting and forging titanium alloys, for it to be accepted in the manufacture of components for critical use such as in the aerospace sector, the properties of the components produced must be as good as, or better than those manufactured using conventional methods.

Ti6Al4V is an alpha-beta alloy that is the most widely used of titanium alloys. Gas tungsten arc welding (GTAW) with wire feeding additive layer manufacture technology deposits titanium mostly like a multipass welding process. Unlike casting, where solidification is usually controlled by nucleation and growth process, arc welding process solidification exhibits mainly epitaxial growth from the adjacent melted substrate. The initial solidifying metal crystallographic orientation is identical to that of the adjoining solid at the fusion line. Fusion welds in titanium alloys are characterized by coarse, columnar-shaped beta grain in the fusion zone due to rapid coarsening in the bodycentred cubic beta phase and grain size typically increases with an increase in thickness. The microstructure of fusion zone significantly affects the mechanical properties. Similar to casting, refining and alternation of grain structure are considered to be beneficial.

Application of alternating longitudinal electromagnetic field, coaxial with welding torch, by a specially designed device attached to the torch, or by low or high frequency pulsed current welding to promote the fluid flow and agitation of the welding pool which is called electromagnetic stirring has been extensively studied to refine the fusion zone of titanium alloys weld. Sundaresan [3] [4] and Balasubramanian [5] [6] reported that the prior beta grain size of pulsed gas tungsten arc welds in thin Ti6Al4V plate was considerably reduced and equiaxial grains were obtained in fusion zone. They attributed it to the oscillation of the weld puddle and reduced temperature gradient caused by external magnetic arc oscillation or pulse current. However, there is no information available on controlling microstructure of GTAW additive layer manufacture Ti6AI4V alloy. A Study by Bernd Baufeld and Omer van der Biest shows that large epitaxial elongated prior beta grains are produced in the SMD Ti6AI4V component which resulted in anisotropic mechanical properties [7]. The RUAM (Ready to Use Additive Manufacture) project, which is funded by an Innovative Manufacturing Research Centre 
(IMRC) grant and industry partners (Airbus, Bombardier, etc.), aims to build large titanium parts by arc welding deposition process for aviation industry.

The objective of this investigation is to show how the direct current pulse GTAW parameters, travel speed and wire feed speed affect the morphology of additive layer manufactured Ti6Al4V.

\section{Experimental}

The materials used in this study is $1.2 \mathrm{~mm}$ in diameter Ti6Al4V wire supplied by VBC group which specification is AMS $4945 \mathrm{G}$. Hot rolled Ti6Al4V $7 \mathrm{~mm}$ thick plates are used as a substrate, which was ground with 400 grit SiC paper, and then degreased with acetone and ethanol before being used. A Migatronic TIG Commander 400 and VBC interpulse IP 150 are used as power sources. The VBC interpulse IP 150 has a constant pulse frequency of $20 \mathrm{kHz}$ when operated in the high frequency mode. It is designed to supply Direct Current, high frequency pulse TIG, low frequency pulse, and a combination of low and high frequency pulse outputs. The power supply unit has a maximum current level of 150A for the main/peak current, background and interpulse currents. The corners of the waveform are rounded off due to the reactance, and the waveform for the high frequency pulse can be assumed as saw tooth. The average current is found by adding the pulse current to the interpulse current and multiplying by $45 \%$, as indicated in Fig. 1. The wire feeder used is a Migatronic KT4 with a maximum wire feed speed of 4 metres per minute. A Fanuc Robot Arc mate 120i is employed to conduct all the additive layer weld depositions. Fig. 2 is a picture of the experiment set-up used in this study. Samples of $180 \mathrm{~mm}$ in length, 20 to $40 \mathrm{~mm}$ in height and $5 \mathrm{~mm}$ in thickness of Ti6Al4V are produced by multilayer deposition. The deposition process is carried out in an open atmosphere with a local argon shielding device. Samples produced at different parameters are cut along longitudinal direction including the substrate. They were mounted, ground, polished and etched for optical examination.

Travel speed (TS), Wire feed speed (WFS), Pulse frequency and the Peak current /Base Current ratio $\left(\mathrm{I}_{\mathrm{p}} / \mathrm{I}_{\mathrm{b}}\right)$ are investigated individually on the effect of morphology of Ti6Al4V TIG deposition walls meanwhile the heat input $\left(n * l_{\text {average }}\right.$ *Voltage/TS, $\eta=0.7[8]$ is efficiency of GTAW) is kept constant for all experiments in order to compare the morphology. The base current $\mathrm{I}_{\mathrm{b}}$ is setup at $45 \mathrm{~A}$ in all pulse welding to ensure enough energy to melt the wire at all times. Table1 is the parameters which used in this study.

Fig. 1 Schematic of low and high frequency pulse TIG welding wave form and average current calculation

Fig. 2 TIG based additive layer manufacturing set-up 
Table 1 is the parameters used in this study

\begin{tabular}{|c|}
\hline $\begin{array}{l}\text { Direct current TIG deposition } \\
\mathrm{I}=98-195 \mathrm{~A}, \mathrm{TS}=0.27-0.54 \mathrm{~mm} / \mathrm{s}, \mathrm{WFS}=1.6-3.2 \mathrm{~m} / \mathrm{min}\end{array}$ \\
\hline $\begin{array}{l}\text { Low frequency pulse TIG deposition } \\
I_{p}=150-345 \mathrm{~A}, I_{b}=45 A I_{\text {average }}=97.5-99 A \\
t_{p}=0.01-0.1 \mathrm{~s} t_{b}=0.01-0.1 \mathrm{~s} \text { frequency }=4.3-25 \mathrm{~Hz} \\
I_{p} / I_{b} \text { ratio }=3.3-8.2 \\
T S=0.27 \mathrm{~m} / \mathrm{min} W F S=1.6 \mathrm{~m} / \mathrm{min}\end{array}$ \\
\hline $\begin{array}{l}\text { High frequency interpulse TIG deposition } \\
I_{p}=150 A, I_{b}=45-75 A I_{\text {interpulse }}=87.5-101 \mathrm{~A} I_{\text {average }}=97.5-99 A \\
t_{p}=t_{b}=0.05 \mathrm{~s} \\
T S=0.27 \mathrm{~m} / \mathrm{min} W F S=1.6-3 \mathrm{~m} / \mathrm{min}\end{array}$ \\
\hline $\begin{array}{l}\text { Heat input } 182 \mathrm{KJ} / \mathrm{m} \text { (constant in all cases) } \\
\text { Average arc voltage }=12 \mathrm{~V}\end{array}$ \\
\hline
\end{tabular}

\section{Result}

\subsection{Morphology affected by $I_{p} / I_{b}$ ratio}

Samples are built at $\mathrm{I}_{\mathrm{p}} / \mathrm{l}_{\mathrm{b}}$ ratios of $3.3,4.0,4.4,5.6,6.7$ and 7.7. Average current and heat input are kept at $99 \mathrm{~A}$ and $182 \mathrm{KJ} / \mathrm{m}$ respectively. It was found that arc pressure increases with $\mathrm{I}_{\mathrm{p}} / \mathrm{l}_{\mathrm{b}}$ ratio. Fig. 3 is a picture of the weld which was deposited at an $\mathrm{I}_{\mathrm{p}} / \mathrm{l}_{\mathrm{b}}$ ratio of 7.7 causing surface breaking defects in the deposition metal. Holes and humps are found in the deposition metal. It is the arc pressure pushing the liquid metal, which comes from the melted substrate and filler wire, to the side of weld path forming holes and humps. A study by Yoshiyushi and Yamamoto [9 and 10] showed that that arc pressure is a function of pulse current. The relationship between arc pressure and $I_{p} / I_{b}$ ratio in this study shows much the same trend as the results reported in [9]. However, the 
macrostructure of beta grain size hasn't been obviously changed as previously reported by the authors [3-6], as indicated in Fig. 4. The equiaxial structure hasn't been achieved by varying the $\mathrm{I}_{\mathrm{p}} / \mathrm{l}_{\mathrm{b}}$ ratio. Large columnar growth prior beta grains developed from substrate to the top of the wall.

Fig. 3 Photograph of pulse GTAW deposition Ti6Al4V with $I_{p} / I_{b}$ ratio at 7.7 , average current $99 A$, travel speed $0.27 \mathrm{~m} / \mathrm{min}$, wire feed speed $1.6 \mathrm{~m} / \mathrm{min}$ shows holes and humps caused by high arc pressure

Fig. 4 Montage of macrostructure of pulse GTAW deposition Ti6Al4V wall with $\mathrm{I}_{\mathrm{p}} / \mathrm{I}_{\mathrm{b}}$ ratio at 6.7, average current is $99 \mathrm{~A}$, travel speed is $0.27 \mathrm{~m} / \mathrm{min}$ and wire feed speed is $1.6 \mathrm{~m} / \mathrm{min}$ shows large columnar growth prior beta grains

\subsection{Morphology affected by frequency}

In order to investigated the macrostructure affected by the frequency of pulsed GTAW, low frequency and high frequency pulsed GTAW (VBC interpulse ) are used to deposit samples at direct current, $5,10,20,25,50 \mathrm{~Hz}$ and $20 \mathrm{kHz}$ levels. Average current and heat input are kept at $99 \mathrm{~A}$ and $182 \mathrm{~J} / \mathrm{mm}$. The macrostructure deposited at different frequency are shown in Fig. 5. Sample (a) and (b) are deposited at 5.3 and $25 \mathrm{~Hz}$ respectively. Sample (c) is deposited in two stages: the first $20 \mathrm{~mm}$ was deposited with low frequency GTAW and the second $20 \mathrm{~mm}$ using $10 \mathrm{~Hz}$ low frequency imposed $20 \mathrm{kHz}$ high frequency GTAW to characterise the effect of high frequency on the refinement of prior beta grains, as indicated in Fig. 1. It can be found that the pulse frequency (low and high frequency) has no great effect on the prior beta grain structure. Large columnar prior beta grains are not broken by both low and high frequency pulsed magnetic fields caused by pulse current and they are well developed through the whole height of the samples.

Fig. 5 Montage of macrostructure of pulse GTAW deposition Ti6Al4V wall with frequency at $5.3 \mathrm{~Hz}$ (a), $25 \mathrm{~Hz}(\mathrm{~b})$, and $10 \mathrm{~Hz}$ low frequency $+20 \mathrm{KHz}$ high frequency (c), average current is $99 \mathrm{~A}$, travel speed is $0.27 \mathrm{~m} / \mathrm{min}$ and wire feed speed is $1.6 \mathrm{~m} / \mathrm{min}$ shows large columnar growth prior beta grains

\subsection{Morphology affected by travel speed}

Macrostructures affected by travel speed are studied under same heat input conditions, which means when travel speed is doubled the deposition current must be doubled at the same time. Fig. 6 is the result which deposited at double travel speed and double 
deposition current comparing with Fig. 4 and 5. The macrostructure of the prior beta grains have no significant difference with those deposited with slow travel speed.

Attempts at travel speed higher than $0.54 \mathrm{~m} / \mathrm{min}$ was attempted during experiments. However, it was too difficult to deposit a stable and even wall when the travel speed is too high for GTAW process.

Fig. 6 Montage of macrostructure of GTAW deposition Ti6Al4V wall with direct current 195A, travel speed $0.54 \mathrm{~m} / \mathrm{min}$, and wire feed speed $3.2 \mathrm{~m} / \mathrm{min}$ shows large columnar growth prior beta grains

\subsection{Morphology affected by wire feed speed}

A multilayer wall, which is $50 \mathrm{~mm}$ in height and $180 \mathrm{~mm}$ in length, is deposited by varied wire feed speed from 1.6 to $3 \mathrm{~m} / \mathrm{min}$ to investigate the effect of wire feed speed on the macrostructure of prior beta grain size (Fig. 7). It is found that the large columnar growth prior beta grains have been blocked from growing when wire feed speed reaches $2.2 \mathrm{~m} / \mathrm{min}$ and equiaxial prior beta grains are established to grow. The deposition was stopped when the wire feed speed reached $3 \mathrm{~m} / \mathrm{min}$ because the arc couldn't melt the extra wire fed to the molten pool.

Fig. 7 Montage of macrostructure of pulse GTAW deposition Ti64 wall with $10 \mathrm{~Hz}$ low frequency plus $20 \mathrm{KHz}$ high frequency, average current is $105 \mathrm{~A}$, travel speed is $0.24 \mathrm{~m} / \mathrm{min}$, the wire feed speed is varied from 1.6 to $3 \mathrm{~m} / \mathrm{min}$ shows large columnar growth prior beta grains have been blocked to grow when wire feed speed is $2.2 \mathrm{~m} / \mathrm{min}$

Base on this experiment a whole equiaxial grain sample has been build with a optimized wire feed speed and welding parameters, such as, peak current, base current, peak time and frequency as indicated in Fig. 8.

Fig. 8 Montage of macrostructure of pulse GTAW deposition Ti64 wall with $10 \mathrm{~Hz}$ low frequency plus $20 \mathrm{KHz}$ high frequency, average current is $105 \mathrm{~A}$, travel speed is $0.24 \mathrm{~m} / \mathrm{min}$, the wire feed speed is $2.2 \mathrm{~m} / \mathrm{min}$. Equiaxial grain growth is achieved through the whole sample 


\section{Discussion}

Static magnetic field has been proved to have a significant effect on the solidification behaviour of cast metal, such as reducing the chemical inhomogeneity, breaking large dendritic arms, and refining the grain size. Magnetic field caused by pulsed welding current has also been shown to have an effect on grain refinement of the weld metal. During arc welding various forces act on the weld pool, these forces include the gravitational force, the surface tension force, the electromagnetic Lorentz force and the plasma jet force [11]. The Direct current arc pressure generated on the weld pool surface can be expressed as [12]:

$$
=
$$

Where $\mu_{0}$ is the magnetic permeability of free space, $I$ is the welding current and $R$ is the arc radius.

For pulse welding the average current and frequency can be expressed respectively by:

$$
\begin{gathered}
= \\
=\square
\end{gathered}
$$

Where $l_{\text {average }}$ is the average current of pulse welding, $I_{p}, l_{b}, t_{p}, t_{b}$ and $f$ are peak current, base current, peak duration time, base duration time and frequency respectively.

Substituting (2) and (3) into (1) gives pulse arc pressure

$$
=+
$$

In order to investigate the influencing amplitude of peak current/base current ratio $=-$ on arc pressure, the Eq. (4) is changed into:

$$
=+
$$

For pulsed arc welding, it can be seen from Eq. (5) that the arc pressure depends on peak current/base current ratio and frequency $f$. The arc pressure increases considerably with increasing peak current/base current ratio, as shown in Fig. 2, the high arc pressure pushes the liquid metal to the side and front of the weld path generating holes and humps when this ratio is too high. Meanwhile it can also be found that there is an optimum frequency (f) producing maximum arc pressure. Indeed, the pulse arc pressure produces enough oscillation causing break up of the dendrite arms to provide more heterogenous nucleation sites refining the grain size in aluminium alloy and some nickel superalloys. However, a study by Abralov and Abdurakhmanov found that titanium solidifies by planar and cellular rather than dendritic growth [13]. There is totally absent fragment dendritic arms which are broken by pulse arc pressure in front of the liquid and solid line to supply heterogenous nucleation sites. That is possibly the reason why we don't find any effective grain refinement by either investigation of the peak current/base current ratio or pulse frequency. 
During the GTAW additive layer manufacture process, the Ti6AI4V substrate at the fusion boundary is heated to the liquidus temperature. In the adjacent $H A Z$, the small equiaxial grains of $\alpha$ and $\beta$ microstructure (in the rolled condition) revert to a fully $\beta$ structure and grow where the $\beta$ transus temperature is exceeded. The $\beta$ grains at the edge of the weld pool act as ideal nucleation sites from which solidification grows into the weld pool. Each growing grain initially forms as a continuation of one of the grains that lie along the part of the fusion boundary. This process is known as epitaxial grain growth. The next layer of $\beta$ grains continue to nucleate and grow from the previously coarsened $\beta$ grains, and combined with the instinctive unidirectional heat flow characteristic of the additive layer manufacturing process causes columnar growth as described in the Fig. 9 and metallurgical observation in the Fig. 5 and Fig. 6.

Fig. 9 Schematic diagram of epitaxial grain grow of additive layer manufactured Ti6Al4V

By adding refractory particles to the weld pool to increase heterogeneous nucleation and to refine fusion zone grain size has been proved is an effective method in many alloys. For GTAW additive layer manufacture process, at a given heat input, by adding more wire restricts the columnar growth of grains. This is due to two reasons; the first is the greater volume of wire acts as more sites for heterogeneous nucleation that can block the columnar growth. Secondly, the higher wire feed rate will result in a negative temperature gradient in front of the liquidus resulting in conditions less likely to promote columnar grain growth and more likely to nucleate equiaxial grains, as indicated in the Fig. 7.

\section{Conclusion}

The morphology of additive layer manufactured Ti6Al4V affected by pulsed gas tungsten arc welding parameters has been systematically studied. It is found that the peak current/base current ratio and pulse frequency don't affect the prior beta grain size significantly. For a given heat input the wire feed rate has a considerable effect on the prior beta grain refinement. Extra wire input can supply much more heterogeneous nucleation sites and also results in negative temperature gradient in the front of the liquidus, which blocks the columnar growth and changes the columnar growth to equiaixal growth.

Acknowledgements

The financial support for this work from Innovative Manufacturing Research Centre (IMRC) and Airbus as well as Bombardier is gratefully acknowledged. 
[1] Herranz. S, Campa. F. J, Lopez de Lacalle. L. N, Rivero. A, Lamikiz. A, Ukar. E, Sanchez. J. A and Bravo. $U$ (2005) The milling of airframe components with low rigidity: a general approach to avoid static and dynamic problems. Proceedings of the Institution of Mechanical Engineers, Part B: Journal of Engineering Manufacture 789-801

[2] Gerd Lutjering and James C Williams (2007) Titanium. Springer Berlin Heidelberg, NewYork.

[3] Sundaresan S and Janaki Ram G. D (1999) Use of magnetic arc oscillation for grain refinement of gas tungsten arc welds in $\alpha-\beta$ titanium alloys. Science and Technology of Welding and Joining 4151-160

[4] Sundaresan S, Janaki Ram G.D, Madhusudhan Reddy G (1999) Microstructural refinement of weld fusion zones in $\alpha-\beta$ titanium alloys using pulsed current welding. Materials Science and Engineering A262: 88-100

[5] Balasubramanian M, Jayabalan V, Balasubramanian V (2008) Effect of microstructure on impact toughness of pulsed current GTA welded $\alpha-\beta$ titanium alloy, Materials Letters 62 :11021106

[6] Kishore Babu N, Ganesh Sundara Raman S, Mythili R, Saroja S (2007) Correlation of microstructure with mechanical properties of TIG weldments of Ti-6Al-4V made with and without current pulsing. Materials Characterization 58: 581-587

[7] Bernd Baufeld and Omer van der Biest(2009) Mechanical properties of Ti6-Al-4V specimens produced by shaped metal deposition, Science and technology of advanced materials $10: 1-10$

[8] Fuerschbach P. W and Knorovsky G. A (1991) A study of melting efficiency in plasma arc and gas tungsten arc welding, Welding journal 11: 287-296

[9] Yoshiyushi Miyamoto, Takashi Nishimura, Yoshihiro Fukuhara, Yuji Koyama, Kenji Narita and Eiichiro Sawahisa(1986). Production of thin wall welded titanium tubes by high frequency pulsed arc welding, Transaction ISIJ, 26: 484-490

[10] Yamamoto H, Harada S, Ueyama T, Ogawa S, Matsuda F, Nakata K (1993) Beneficial effect of low frequency pulsed MIG welding on grain refinement of weld metal and improvement of solidification crack susceptibility of aluminium alloys: Study of low-frequency pulsed MIG welding, Welding international, 7: 456-461

[11] Kim, Y S and Eagar, T. W (1993) Analysis of metal transfer in gas metal arc welding, Welding Journal, 72 (6): 269s-278s

[12] Lin, M. L and Eagar, T. W (1986) Pressures produced by gas tungsten arcs, Metallurgical Transactions B, 17B (3): 601-607

[13] Abralov, M.A, Abdurakhmanov, R.U and luldashev, A.T (1978) The effect of electromagnetic action on the primary solidification of titanium. Welding Production 25(5):1-3 


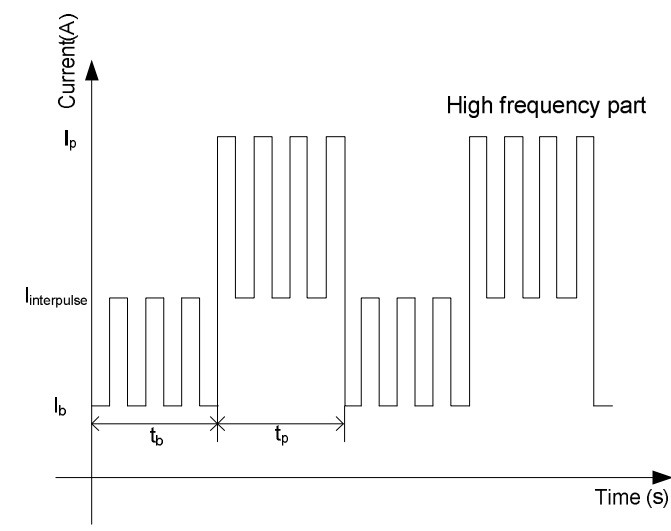

$I_{\text {average }}=\frac{\left(I_{\text {int erpulse }}+I_{p}\right) \times 0.45 t_{p}+\left(I_{\text {int erpulse }}+I_{b}\right) \times 0.45 t_{b}}{t_{p}+t_{b}}$

Fig. 1 Schematic of low and high frequency pulse TIG welding wave form and average current calculation

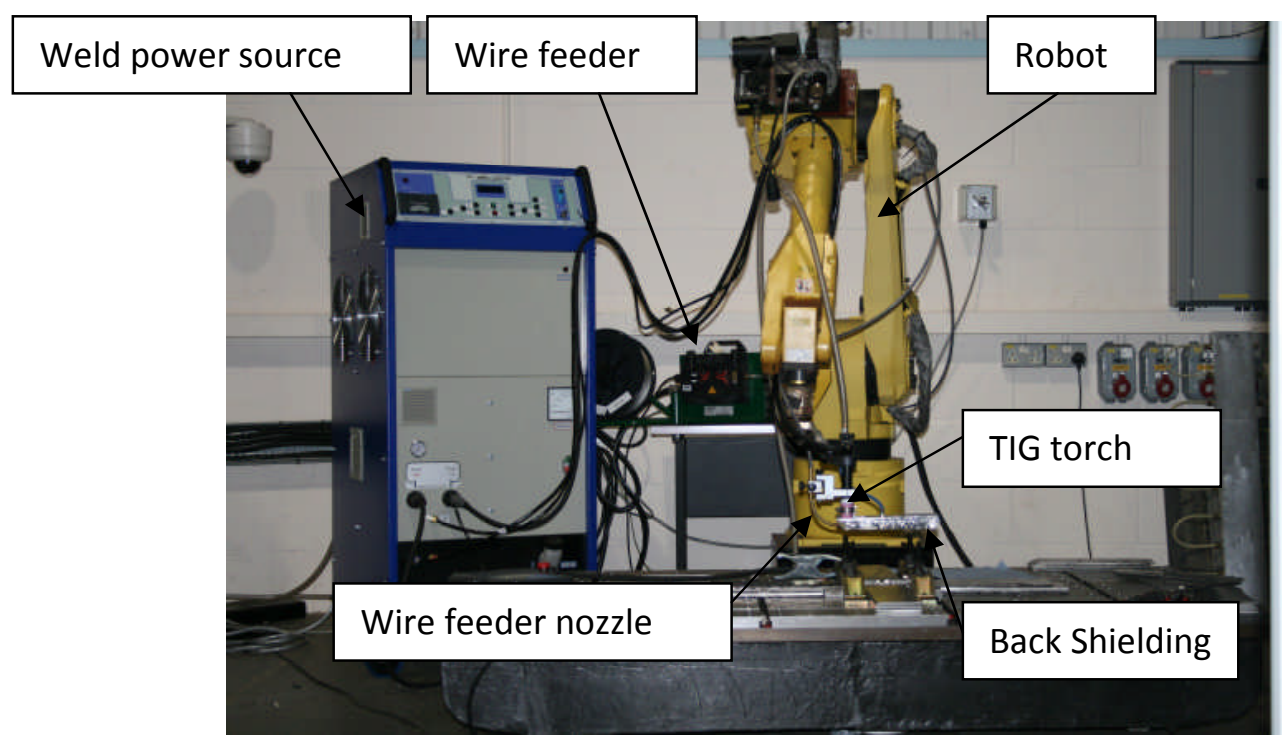

Fig. 2 TIG based additive layer manufacturing set-up

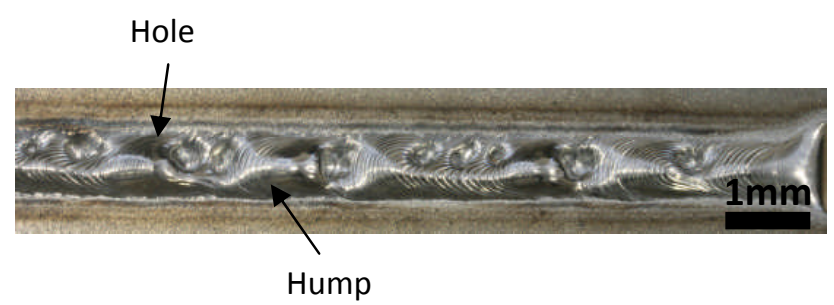


Fig. 3 Photograph of pulse GTAW deposition Ti6Al4V with $I_{p} / I_{b}$ ratio at 7.7 , average current 99A, travel speed $0.27 \mathrm{~m} / \mathrm{min}$, wire feed speed $1.6 \mathrm{~m} / \mathrm{min}$ shows holes and humps caused by high arc pressure

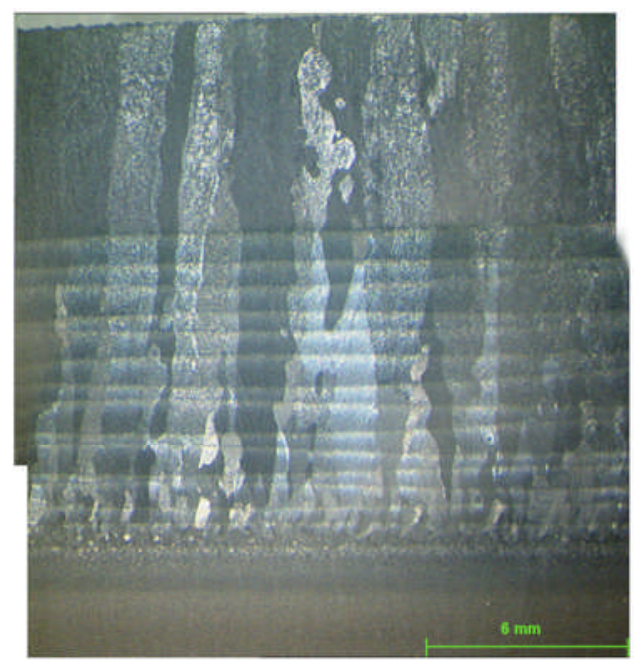

Fig. 4 Montage of macrostructure of pulse GTAW deposition Ti6Al4V wall with $\mathrm{I}_{\mathrm{p}} / \mathrm{I}_{\mathrm{b}}$ ratio at 6.7, average current is $99 \mathrm{~A}$, travel speed is $0.27 \mathrm{~m} / \mathrm{min}$ and wire feed speed is $1.6 \mathrm{~m} / \mathrm{min}$ shows large columnar growth prior beta grains, the scale bar is $6 \mathrm{~mm}$
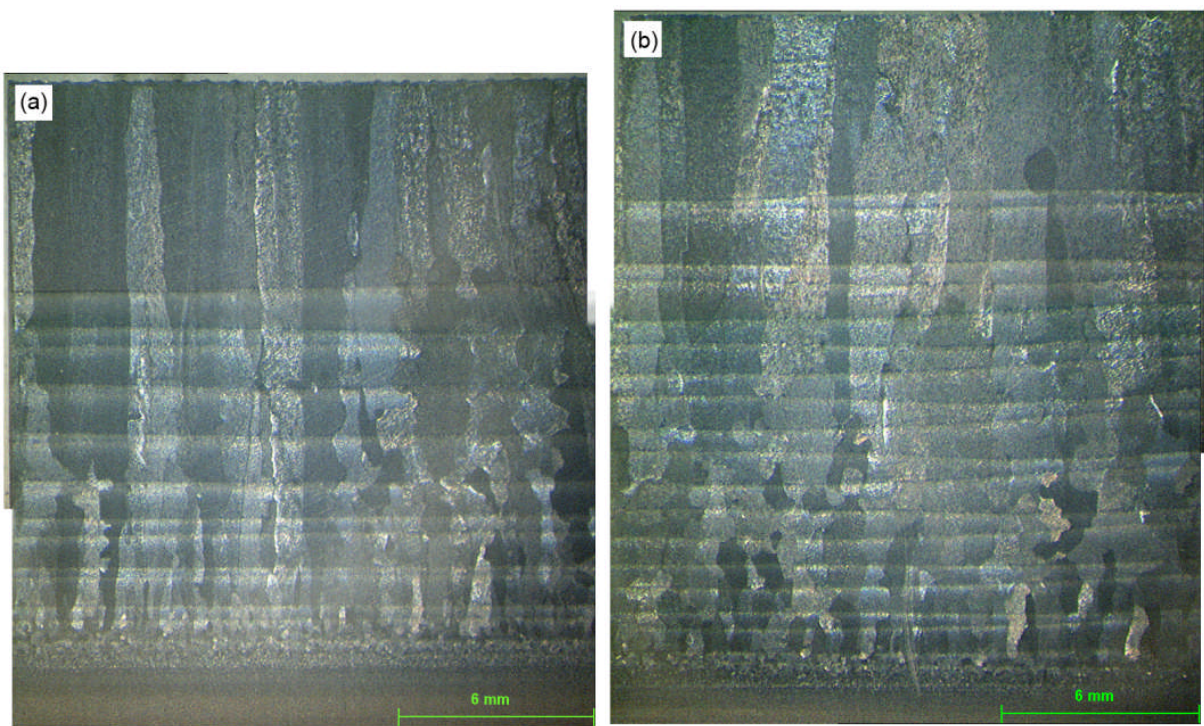


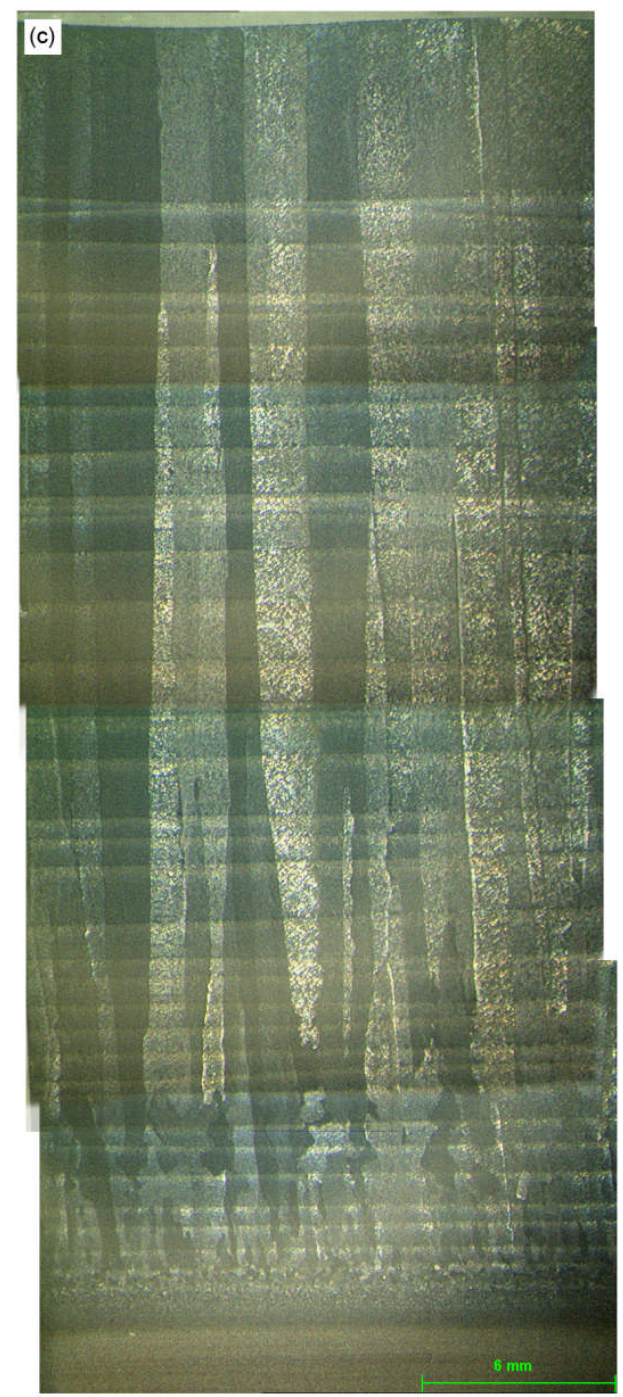

Fig. 5 Montage of macrostructure of pulse GTAW deposition Ti6Al4V wall with frequency at $5.3 \mathrm{~Hz}$ (a), $25 \mathrm{~Hz}$ (b), and $10 \mathrm{~Hz}$ low frequency $+20 \mathrm{KHz}$ high frequency (c), average current is $99 \mathrm{~A}$, travel speed is $0.27 \mathrm{~m} / \mathrm{min}$ and wire feed speed is $1.6 \mathrm{~m} / \mathrm{min}$ shows large columnar growth prior beta grains, the scale bar is $6 \mathrm{~mm}$ 


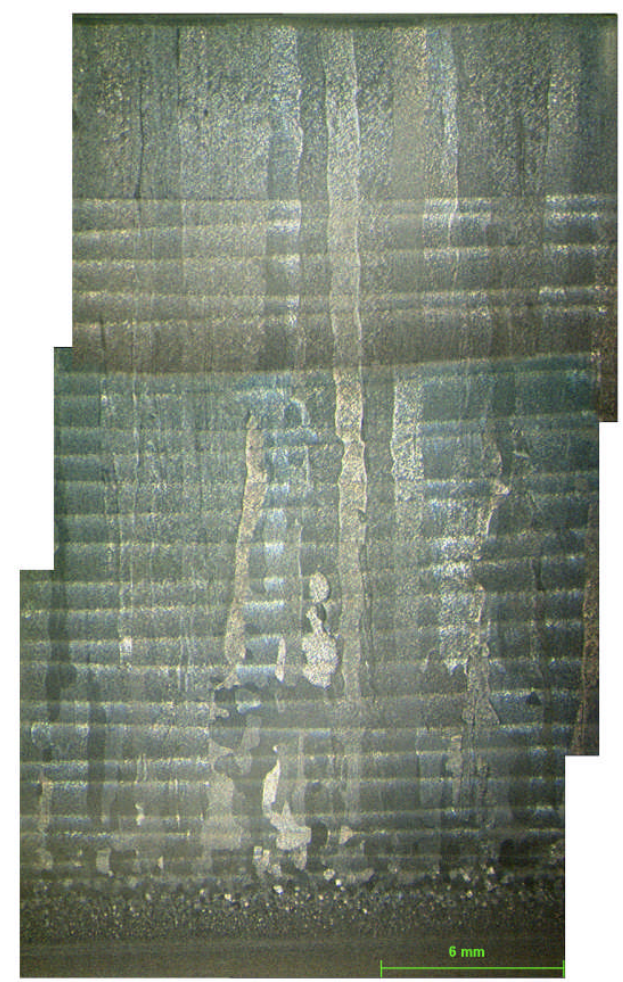

Fig. 6 Montage of macrostructure of GTAW deposition Ti6Al4V wall with direct current 195A, travel speed $0.54 \mathrm{~m} / \mathrm{min}$, and wire feed speed $3.2 \mathrm{~m} / \mathrm{min}$ shows large columnar growth prior beta grains, the scale bar is $6 \mathrm{~mm}$ 


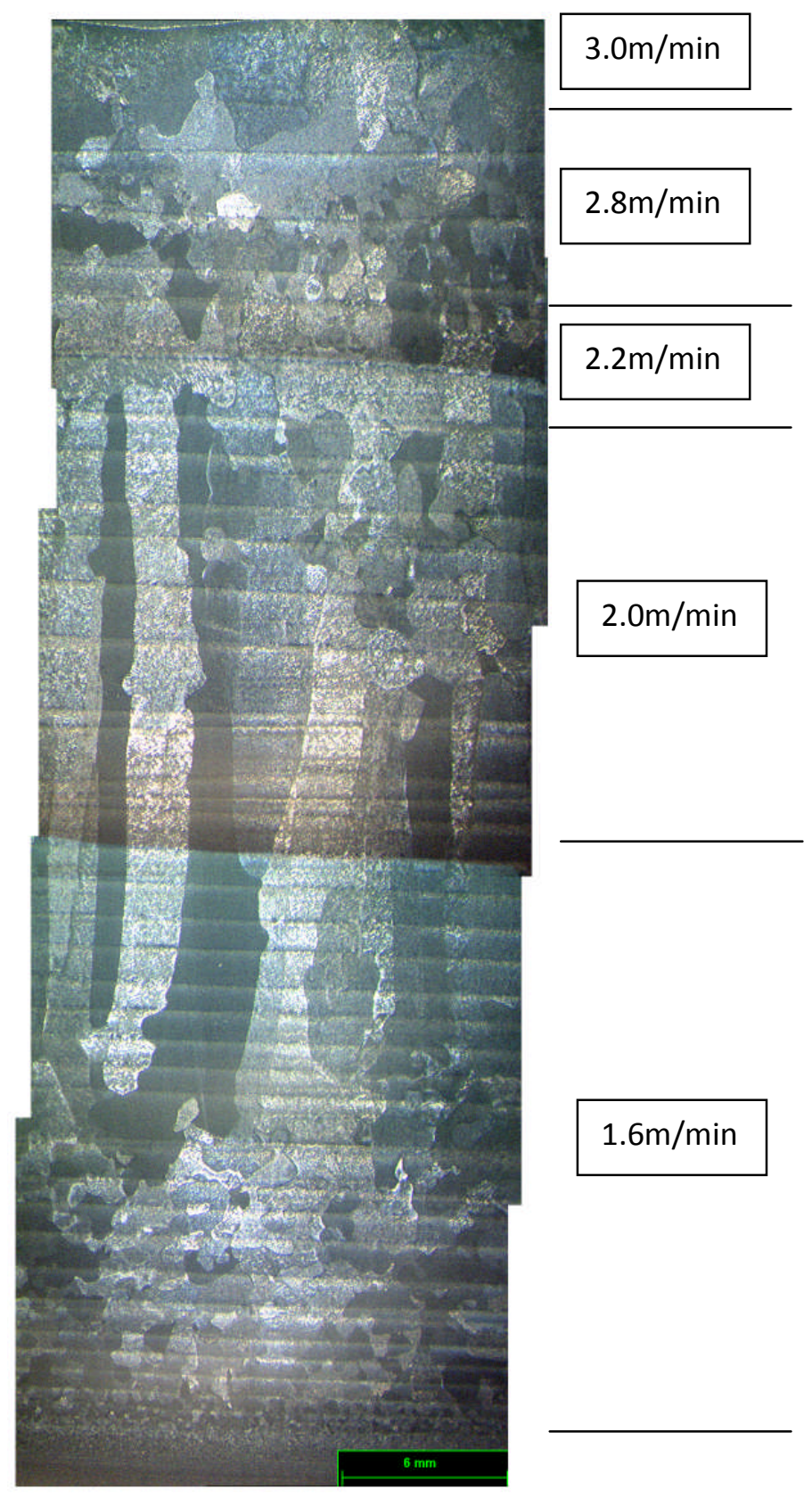

Fig. 7 Montage of macrostructure of pulse GTAW deposition Ti64 wall with $10 \mathrm{~Hz}$ low frequency plus $20 \mathrm{KHz}$ high frequency, average current is $105 \mathrm{~A}$, travel speed is $0.24 \mathrm{~m} / \mathrm{min}$, the wire feed speed is varied from 1.6 to $3 \mathrm{~m} / \mathrm{min}$ shows large columnar growth prior beta grains have been blocked to grow when wire feed speed is $2.2 \mathrm{~m} / \mathrm{min}$, the scale bar is $6 \mathrm{~mm}$ 


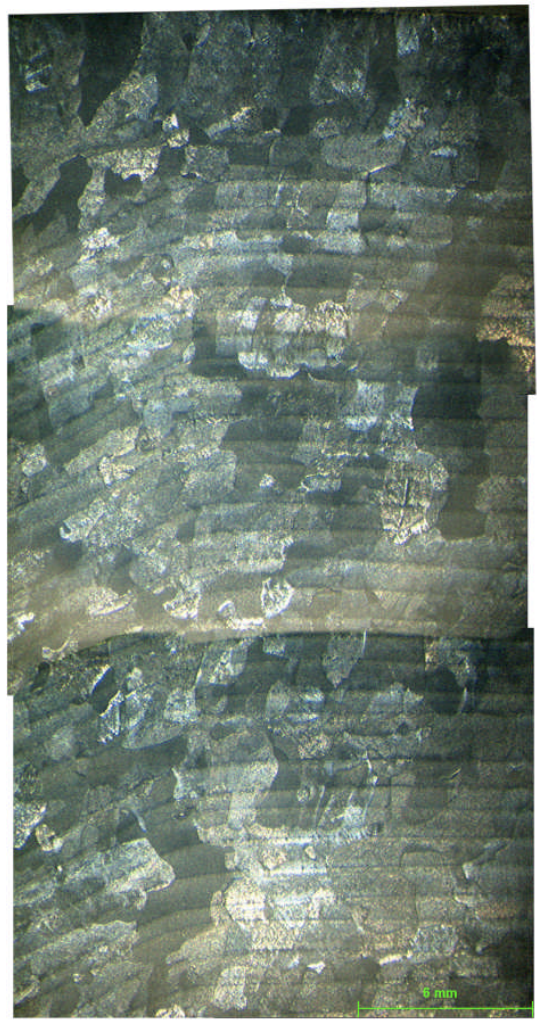

Fig. 8 Montage of macrostructure of pulse GTAW deposition Ti64 wall with $10 \mathrm{~Hz}$ low frequency plus $20 \mathrm{KHz}$ high frequency, average current is $105 \mathrm{~A}$, travel speed is $0.24 \mathrm{~m} / \mathrm{min}$, the wire feed speed is $2.2 \mathrm{~m} / \mathrm{min}$. Equiaxial grain growth is achieved through the whole sample, the scale bar is $6 \mathrm{~mm}$

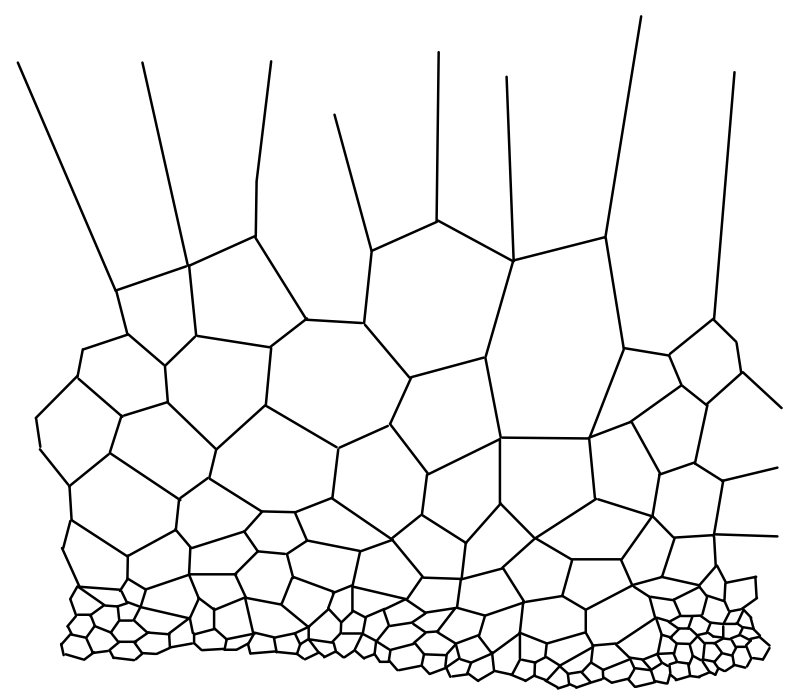

Fig. 9 Schematic diagram of epitaxial grain grow of additive layer manufactured Ti6Al4V 